\title{
Penanaman Cinta Lingkungan Pada Masyarakat PAUD
}

\author{
Titi Chandrawati, Siti Aisyah \\ Universitas Terbuka \\ titich@ecampus.ut.ac.id sitia@ecampus.ut.ac.id
}

Received: 13 August 2021; Revised: 02 October 2021; Accepted: 24 December 2021

DOI: http://dx.doi.org/10.37905/aksara.8.1.131-136.2022

\begin{abstract}
Abstrak
Mencintai lingkungan adalah suatu karakter anak yang harus ditanamkan kepada masyarakat Indonesia sejak usia dini. Untuk itu, masyarakat PAUD perlu dikenalkan dengan literasi lingkungan karena masih banyak masyarakat PAUD yang belum paham akan literasi lingkungan. Pemahaman dan keterampilan literasi lingkungan jika dipelajari oleh seseorang sejak usia dini, maka ilmu tersebut dapat menjadi kebiasaan dan akan bertahan lama dalam pikiran dan hati seseorang. Artikel ini akan menguraikan bagaimana upaya menanamkan cinta lingkungan kepada masyarakat PAUD yang dilakukan tim peneliti. Penelitian ini menggunakan metode penelitian tindakan tdengan pemberian informasi dan motivasi tentang pentingnya Pendidikan Lingkungan Hidup (PLH) kepada anak usia dini. Subjek yang terlibat dalam kegiatan ini adalah masyarakat PAUD yang diwakili oleh 11 guru PAUD di daerah Tangerang, Sawangan Bogor, Medan, dan Batam. Artikel ini ditulis berdasarkan hasil Penelitian Tindakan dengan pendekatan kualitatif melalui diskusi dan wawancara dan penyampaian informasi melalui temu online mengenai PLH untuk PAUD. Periode pengumpulan data memakan waktu 4 bulan pada tahun 2020. Analisis isi digunakan untuk menganalisis data dalam penelitian ini. Data yang diperoleh divalidasi oleh anggota fakultas. Temuan dari penelitian ini menunjukkan bahwa adanya pemberian informasi dan pemberian motivasi kepada 11 guru PAUD tersebut dapat membuat 9 orang guru tergugah untuk ikut mempelajari dan mengajarkan literasi lingkungan kepada anak didiknya. Para guru tersebut berupaya membuat lingkungan sekolah menjadi lebih hijau dengan menanam pohon dan membuat berbagai kegiatan pembelajaran bersama anak untuk lebih mengenal dan sayang lingkungan.
\end{abstract}

Kata kunci: literasi lingkungan, Pendidikan Lingkungan Hidup, penelitian tindakan, menyayangi dan melestarikan lingkungan

\section{LATAR BELAKANG}

Setiap tahun masyarakat Jakarta dan sekitarnya serta masyarakat di berbagai wilayah di Indonesia sering mengalami musibah banjir besar. Ada juga daerah yang mengalami musibah tanah longsor. Masalah lainnya adalah pembuangan limbah pabrik atau sampah. Masalah negeri ini adalah banyaknya orang yang membuang sampah secara sembarangan ke sungai dan mengalir ke laut. Fakta-fakta ini menunjukkan kurangnya kesadarang masyarakat akan masalah lingkungan hidup. Oleh sebab itu tim peneliti ingin berupaya menanamkan dan mengembangkan wawasan masyarakat tentang literasi lingkungan. Literasi lingkungan menurut Kusumaningrum (2018) adalah adanya kesadaran seseorang untuk menjaga lingkungan agar tetap seimbangan. Kesadaran tersebut dapat pula diartikan sebagai sikap melek lingkungan, yaitu kondidi dimana 
seseorang tidak hanya memiliki pengetahuan tentang lingkungan namun juga memiliki sikap tanggap dan mampu memberikan solusi atas isu-isu lingkungan. Anak usia dini merupakan generasi emas atau bagian masyarakat yang perlu dibekali kemampuan literasi lingkungan sejak mereka kecil agar kemampuan tersebut terbawa sampai mereka dewasa kelak (Siregar, Meilani, Purwanto, 2021).

Tantangan saat ini dalam mengedukasi masyarakat dan anak-anak untuk lebih peka terhadap masalah lingkungan hidup diantaranya karena kurangnya edukasi lingkungan dari orang tua si anak, masyarakat masih belum sadar terhadap masalah lingkungan sehingga edukasi lingkungan harus lebih intensif dilakukan melalui pendidikan agama, sekolah dll. Oleh sebab itu, dalam mengedukasi suatu masyarakat khususnya anak-anak usia dini, sekolah harus bekerjasama dengan orang tua murid dan masyarakat sekitarnya. Penelitian mengupayakan bahwa dalam penanaman kesadaran anak untuk cinta lingkungan mensyaratkan adanya dukungan dari orang tua anak itu sendiri (http://dlh.jabarprov.go.id/index.php/layanan/k2-categories-2/item/62pentingnya-pendidikan-lingkungan).

Pendidikan lingkungan hidup berperan penting dalam pelestarian dan perbaikan lingkungan di dunia, dalam mewujudkan hidup yang berkelanjutan. Sebuah tujuan dasar dari pendidikan lingkungan adalah untuk membuat individu dan masyarakat memahami sifat kompleks alam dan lingkungan dibangun dihasilkan dari interaksi aspek biologi, fisik, sosial, ekonomi, dan budaya mereka, dan memperoleh pengetahuan, nilai-nilai , sikap, dan keterampilan praktis untuk berpartisipasi dalam cara yang bertanggung jawab dan efektif dalam mengantisipasi dan memecahkan masalah lingkungan, dan dalam pengelolaan kualitas lingkungan (http://dlh.jabarprov.go.id/index.php/layanan/k2categories-2/item/62-pentingnya-pendidikan-lingkungan).

Pentingnya pendidikan lingkungan hidup untuk hidup yang berkelanjutan harus diterapkan di masayarakat mulai dari usia dini. Setiap sekolah harus bisa mengajak dan memperkenalkan terhadap siswa/siswi dalam memahami kondisi alam dan masalah alam saat ini. Salah satu contoh dalam mengajak anak usia dini untuk sadar akan lingkungan melalui pemberian contoh kecil yakni membuang sampah pada tempatnya. Guru dan orang tua perlu memperkenalkan masalah lingkungan yang sedang terjadi saat ini dan pencegahannya untuk di masa depan terhadap anak-anak. Selanjutnya guru dan orang tua harus bekerjasama dalam mengajak anak-anak untuk praktek kesadaran lingkungan secara langsung seperti belajar menanam sayur-sayuran. Hal yang terjadi saat ini banyak orang tua yang tidak pernah memperkenalkan anak-anaknya tentang lingkungan. Bahkan saat ini banyak sekali anak-anak SMP atau SMA yang tidak tahu nama-nama sayuran karena tidak pernah di dikenalkan oleh orang tuanya (http://dlh.jabarprov.go.id/index.php/layanan/k2-categories-2/item/62-pentingnya-

pendidikan-lingkungan). Berdasarkan masalah-masalah di atas maka penelitian ini berupaya menanamkan kesadaran masyarakat akan lingkungan melalui penanaman literasi lingkungan yang dimulai dengan pengembangan literasi lingkungan di sejumlah taman kanak-kanak dan PAUD di beberapa wilayah di Indonesia.

\section{Meningkatkan Kesadaran Lingkungan Di Antara Anak-Anak}

Pendidikan dasar adalah tahap penting dalam pengembangan perilaku seseorang, kesadaran sosial dan tidak mementingkan diri sendiri. Di sekolah kita belajar nilai-nilai dan perilaku yang akan tetap bersama kita sepanjang masa dewasa kita dan menentukan 
siapa kita. Itulah yang membuatnya begitu penting untuk memicu minat merawat dan melindungi lingkungan saat anak-anak masih di sekolah (https://www.iberdrola.com/environment/enviromental-education-for-kids).

Tujuan mengajar anak-anak tentang pendidikan lingkungan adalah agar mereka merawat alam sebagai bagian dari kehidupan mereka, bukan hanya mempelajarinya. Gagasan di balik subjek ini adalah agar kaum muda mengembangkan pola pikir ekologis yang kuat dan menggunakannya untuk mengatasi tantangan lingkungan saat ini dengan sikap proaktif dan komitmen yang kuat (https://www.iberdrola.com/environment/enviromental-education-for-kids).

Pendidikan lingkungan juga memiliki efek positif lain pada kaum muda. Pada 2017, Universitas Stanford mempelajari bagaimana hal ini mempengaruhi anak-anak sekolah dari sekolah bayi hingga sekolah menengah. Setelah meneliti lebih dari seratus studi ilmiah yang diterbitkan pada subjek dari 1994 hingga 2013 oleh lembaga lain, mereka menyimpulkan bahwa $83 \%$ anak sekolah meningkatkan perilaku ekologis mereka dan 98\% mendapat nilai lebih baik di mata pelajaran lain seperti matematika dan sains (https://www.iberdrola.com/environment/enviromental-education-for-kids).

\section{Metode Pendidikan Lingkungan Untuk Anak-Anak}

Pendidikan lingkungan adalah proses seumur hidup dan harus dimasukkan dalam setiap silabus sekolah dasar dan menengah, serta dalam kegiatan lain seperti seminar, konferensi, dan pembicaraan. Cara itu diajarkan di kelas harus disesuaikan dengan usia dan kematangan anak-anak dan harus tidak hanya teoritis tetapi juga praktis, menghibur dan menyenangkan.Ada banyak kegiatan yang bisa dilakukan di taman bermain atau di taman terdekat. Anak-anak dapat pergi keluar rumah untuk belajar tentang tanaman, pohon, sungai, burung dan serangga, tetapi juga tentang masalah lingkungan seperti polusi, emisi gas, konsumsi energi, daur ulang, penggunaan air yang baik dan seluruh aspek penting lainnya (https://www.iberdrola.com/environment/enviromental-educationfor-kids).

\section{Tujuan Pendidikan Lingkungan Untuk Anak-anak}

Menurut UNESCO, tujuan anak-anak belajar tentang pendidikan lingkungan (https://www.iberdrola.com/environment/enviromental-education-for-kids) adalah agar.:

- membuat mereka lebih sadar dan sadar akan masalah lingkungan.

- meningkatkan minat mereka dalam merawat dan memperbaiki lingkungan.

- meningkatkan kemampuan mereka untuk belajar tentang lingkungan mereka.

- memperluas pengetahuan ekologis mereka dalam mata pelajaran seperti energi, lanskap, udara, air, sumber daya alam, dan margasatwa.

Mengajar generasi baru terserah kita semua, bukan hanya orang tua. Anak-anak hari ini akan menjadi gubernur dan pemimpin dunia masa depan dan mereka harus menghadapi tantangan besar - seperti pemanasan global dan tekanan air - dan membuat keputusan penting untuk semua umat manusia. Masa depan ada di tangan mereka (https://www.iberdrola.com/environment/enviromental-education-for-kids).

\section{Metode Penelitian}

Penelitian ini menggunakan penelitian tindakan karena menurut Arikunto definisi penelitian tindakan adalah penelitian tentang hal-hal yang terjadi di masyarakat atau 
kelompok sasaran, dan hasilnya langsung dapat dikenakan pada masyarakat yang bersangkutan (https://www.duniapengertian.com/2017/10/pengertian-penelitiantindakan-serta.html?m=1). P

Pemilihan penelitian tindakan pada penelitian ini karena sesuai dengan permasalahan sosial yang dihadapi terutama pada guru anak usia dini karena bertujuan untuk mengatasi berbagai permasalahan yang terjadi di dalam situasi sosial. Menurut Suharso

(http://staffnew.uny.ac.id/upload/131411082/pengabdian/PENELITIAN+TINDAKAN_

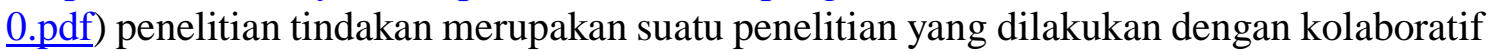
(kerjasama) berdasarkan hasil reflektif (perenungan atau penilaian) yang dilakukan oleh guru bekerja sama dengan pihak lain yang terkait untuk memperbaiki suatu masalah kependidikan. Tujuan penelitian tindakan adalah merupakan gerakan guru sebagai peneliti, yang tujuannya mengurangi kesenjangan antara theory dan practice.

Penelitian ini berupaya menyampaikan informasi mengenai Pendidikan Lingkungan Hidup (PLH) kepada 11 guru PAUD sebagai responden atau subjek penelitian melalui daring dengan materi: Permasalahan lingkungan hidup, Literasi lingkungan untuk PAUD, Pembelajaran lingkungan hidup di PAUD. Penyampaian informasi ini dilakukan melalui daring, berupa webinar PLH untuk PAUD karena sedang ada pandemic covid 19 dan karena subjek penelitian kami ada di Medan, Batam, Tangerang, Sawangan. Selanjutnya peneliti mencari tahu sejauh mana pengetahuan dan pemahaman guru-guru PAUD tersebut tentang literasi lingkungan terkait dengan PLH, terutama bagaimana para guru PAUD dapat mengajar pendidikan lingkungan hidup dalam situasi pandemi ini melalui pembelajaran daring dan luring.

Tim peneliti kemudian mengirimkan pertanyaan terbuka kepada semua subjek penelitian dan berdiskusi dan menjelaskan kembali informasi mengenai literasi lingkungan terkait dengan PLH kepada 11 guru PAUD sebagai responden atau subjek penelitian. Penelitian Tindakan ini dilakukan dengan pendekatan kualitatif, karena peneliti dapat mengenal subjek penelitian dan dapat saling berdialog. Periode pengumpulan data memakan waktu 4 bulan, Agustus- November 2020. Analisis isi digunakan untuk menganalisis data dalam penelitian ini. Data yang diperoleh divalidasi oleh seorang dosen senior di FKIP-UT.

Pemberian informasi mengenai PLH dan literasi lingkungan dilakukan tim peneliti melalui webinar atau temu online dengan beberapa nara sumber. Contoh strategi pengajaran yang guru TK/PAUD lakukan sangat terkait dengan tema misal tema lingkungan atau tanaman misalnya mengajar anak usia dini melalukan beberapa kegiatan seperti membersihkan halaman, menyapu dan membantu ibu membersihkan dan merapikan rumah, menyiram tanaman, dan menanam beberapa tanaman.

\section{Hasil Penelitian dan Diskusi}

Berdasarkan wawancara dengan 11 guru PAUD/TK maka diperoleh hasil bahwa sebelumnya mereka belum terlalu sadar dan belum mengenal atau belum memahami secara lengkap apa yang dimaksud dengan literasi lingkungan. Namun setelah diberikan pengarahan dan informasi kepada 11 guru PAUD yang menjadi subjek penelitian ini maka mereka menyatakan bahwa mereka sekarang menjadi lebih tahu tentang literasi lingkungan dan mereka mulai memberikan kegiatan pembelajaran terkait PLH kepada anak didiknya. Ke 11 guru PAUD tersebut juga menjelaskan bahwa mereka telah 
melakukan beberapa strategi pengajaran yang mengarah pada membuat anak didik usia dini belajar tentang literasi lingkungan atau pendidikan lingkungan.

Lebih jauh, ada 11 guru TK/PAUD dari 11 subjek penelitian yang juga menyatakan bahwa dengan mengikuti kegiatan ini mereka menjadi sadar pentingnya mengembangkan literasi lingkungan kepada anak didik mereka. Oleh sebab itu mereka mulai membacakan buku cerita terkait PLH, mulai meminta anak didik untuk menanam pohon atau menyirami pohon bagi anak yang di rumahnya sudah ada tanaman atau meminta anak didik untuk ikut membantu membersihkan rumah dan sekolahnya. Berikut adalah salah satu pendapat subjek penelitian ini tentang pengaruh mengikuti kegiatan penanaman cinta lingkungan:

Subjek 1:

"Dengan adanya PLH literasi cinta lingkungan saya sebagai guru paud dapat memberikan stimulasi kepada anak2 bagaimana harus menjaga dn melestarikan lingkungan, anak mnjadi faham bhwa kita harus mnjaga kebersihan.tidak membuang sampah sembarangan. Karena membuang sampah dapat menyebabkan banjir/ bencana alam. Anak sangat tertarik saat kita melakulan pengembangan sosialisasi literasi cinta lingkungan"

Subjek 2:

Mengikuti kegiatan upaya menanamkan cinta lingkungan kepada anak usia dini ini membuat saya sebagai guru berupaya mengajak anak didik saya untuk berjalan-jalan sekita sekolah dan memperhatikan lingkungan yang bersih dan yang kotor dan kemudian mengajak anak berdiskusi tentang bagaimana membuat lingkungan selalu bersih dengan selalu membuang sampah pada tempatnya.. Saya bahkan merasa terharu melihat ada murid saya yang mengingatkan orang agar mau membuah sampah di tempat sampah.

Subjek penelitia juga mengirimkan beberapa foto berisi kegiatan anak usia dini yang telah melaksanakan kegiatan cinta lingkungan hidup sebagai berikut.

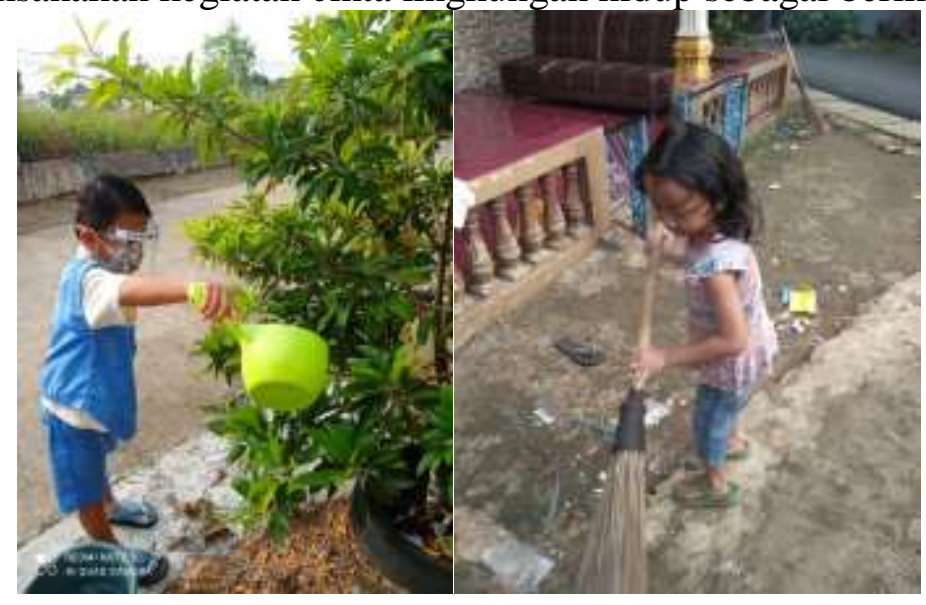

Kegiatan-kegiatan yang telah dilakukan oleh para subjek penelitian sebagai guru PAUD telah menunjukkan bahwa walaupun adanya pandemic covid membuat kegiatan pembelajaran tidak bisa selalu bertemu tatapmuka namun kegiatan belajar anak untuk cinta lingkungan tetap dapat dilaksanakan. Hal ini juga menunjukkan bahwa kegiatan penyampaian informasi dan pemberian motivasi kepada pada subjek penelitian telah membuat mereka menyadari pentingnya untuk mengajarkan dan membiasakan anak usia dini untuk cinta lingkungan sejak dini 


\section{KESIMPULAN}

Meskipun pada awalnya para guru PAUD/TK belum begitu memahami konsep literasi lingkungan, namun dengan mengikuti kegiatan penelitian Tindakan dari tim peneliti dapat membantu para guru PAUD untuk mengenal apa maksud literasi lingkungan dan bagaimana penerapannya di TK/PAUD. Subjek penelitian juga sudah menggunakan beberapa strategi pengajaran untuk membantu siswa usia dini mereka menjadi literasi lingkungan. Walaupun strategi mengajar yang digunakan guru berbedabeda antara satu dengan yang lainnya namun intinya, para guru berupaya menanamkan cinta lingkungan kepada muridnya yang berusia dini. Dari penelitian tersebut tersirat bahwa meskipun anak usia dini harus belajar di rumah tetapi guru PAUD mereka tetap dapat mengajarkan anak didiknya untuk mulai menjaga dan melestarikan lingkungan mereka.

\section{REFERENSI}

Benefits of environmental education in kids, https://www.iberdrola.com/environment/enviromental-education-for$\underline{\text { kids }}$

Cherry, Kendra. "Social Learning Theory: An Overview of Bandura's Social Learning Theory." Artikel yang tersedia secara online dalam .

Djoehaeni, H. (2014), Model Pembelajaran Pendidikan Lingkungan Hidup Pada Pendidikan Anak Usia, Edutech, Tahun 13, Vol.1, No.1, Februari 2014

Diana Kusumaningrum (2018), LINGKUNGAN DALAM KURIKULUM 2013 DAN PEMBELAJARAN IPA DI SD, Indonesian Journal of Natural Science Education (IJNSE) Volume 01, Nomor 02, 2018, pp: 57 64 p-ISSN: 2621-8747, e-ISSN : 2621-8755 e-mail: ijnse@ untidar.ac.id,

Enggar Harususilo, Y.(2019),Waspadai, Bahaya Anak Tidak Memiliki "Literasi Lingkungan"",https://edukasi.kompas.com/read/2019/02/20/22201031/waspadai -bahaya-anak-tidak-memiliki-literasi-lingkungan.

Fajrin, Latifah Permatasari (2020), Pendidikan Lingkungan Hidup Di Raudhatul Athfal, Jurnal Tunas Siliwangi ISSN : 2476-9789 (Print) 2581-0413 (Online) Vol. 6, No. 2

Klikhijau.com (2021), Ragam Ide Pendidikan Lingkungan untuk Anak Usia Dini!,https://klikhijau.com/read/ragam-ide-pendidikan-lingkungan-untukanak-usia-dini/

Masyunita Siregar, Sri Martini Meilani, Agung Purwanto (2021), Pengenalan Ecoliteracy pada Anak Usia Dini melalui Metode Bercerita Jurnal Obsesi : Jurnal Pendidikan Anak Usia Dini ISSN: 2549-8959 (Online) 2356-1327 (Print) Volume 5 Issue 1 (2021) Pages 719-728

Sagino (2019), Sekolah Berbasis Literasi Lingkungan Sebuah Destinasi Akrab dan Peduli Lingkungan, , http://jatengpos.co.id/sekolah-berbasis-literasi-lingkungansebuah-destinasi-akrab-dan-peduli-lingkungan/)

Pentingnya Pendidikan Lingkungan, http://dlh.jabarprov.go.id/index.php/layanan/k2categories-2/item/62-pentingnya-pendidikan-lingkungan.

Parker, Lyn \& Prabawa-Sear, Kelsy, 2020, Environmental Education in Indonesia: Creating Responsible Citizens in the Global South 